\title{
A Comprehensive School-Based Nutrition Intervention to Improve the Implementation of Healthy School Canteen Policy: A Systematic Review
}

\author{
Sarah At Tauhidah, Cicilya Candi, Adang Bachtiar
}

Health Policy and Administration Department, Faculty of Public Health, Universitas Indonesia

\section{ABSTRACT}

Background: School-based nutrition intervention is recommended as one of the public health strategies in supporting the development of healthy diet behaviour for school-age children. It is in line with Global Action Plan 2013-2020 of World Health Organization (WHO) in preventing and controlling double burden of disease as a consequence of non-communicable disease in the future. This study aims to identify the kind of comprehensive school-based nutrition intervention and analyze effectiveness of every study in improving policy implementation of healthy school canteen.

Subjects and Method: This systematic review study was conducted from two electronic databases, namely Scopus and ProQuest with keywords of "school nutritional policy", "comprehensive intervention", and "healthy canteen" to search relevant publication in English and have open access published from 2015 to 2020.

Results: From total 1.367 of publications, 9 articles meet inclusion criteria. Based on evaluation of those studies with comprehensive or multicomponent intervention to healthy school canteen policy, the common elements show that regular monitoring and feedback with executive and community support can show improvement of school adherence to policy implementation.

Conclusion: This study found that a comprehensive school-based nutrition intervention was effective in improving the implementation of healthy school canteen policy.

Keywords: nutrition intervention, healthy canteen, policy implementation

\section{Correspondence:}

Sarah At Tauhidah. Health Policy and Administration Department, Faculty of Public Health, Universitas Indonesia. F Building 1st Floor, Kampus Baru UI Depok 16424, Indonesia. Email: Sarah.at@ui.ac.id.

\section{Cite this as:}

Tauhidah SA, Candi C, Bachtiar A (2021). A Comprehensive School-Based Nutrition Intervention to Improve the Implementation of Healthy School Canteen Policy: A Systematic Review. J Health Policy Manage. 06(01): 57-66. https://doi.org/10.26911/thejhpm.2021.06.01.06.

cc (i) (-) Journal of Health Policy and Management is licensed under a Creative Commons EY NC SA Attribution-Non Commercial-Share Alike 4.0 International License.

\section{BACKGROUND}

The 2017 Global Burden of Disease study reported that 11 million deaths were attributable to dietary risk factors. High intake of sodium (3 million deaths), low intake of whole grains ( 3 million deaths), and low intake of fruits ( 2 million deaths) were the leading dietary risk factors for deaths and disability-adjusted life-years (DALYs) globally and in many countries (Afshin et al., 2019). Considering the significance of social and environmental factors in forming diet and habit, a population-based approach should be the main component. An effective strategy could be designed and applied at the local level, such as school, workplace, and community environment, at regional level, or global (Initiatives, 2020).

A school-based nutrition intervention is recommended as one of the healthy dietary habits for students (Carter and Swinburn, 2004). It is because students spend almost 
$40 \%$ of their daily energy intakes in school (Mansouri, 2007). School is also functioned as an involvement meeting point for students, families, educational institution, as well as community (Briggs, Fleischhacker and Mueller, 2010). In addition, the schoolbased nutrition intervention is also in line with Global Action Plan 2013-2020 of World Health Organization (WHO) in preventing and controlling global burden of disease as a consequence of no communicable diseases in the future (WHO, 2013).

Many countries including Australia, England, and United States have introduced nutrition policies requiring schools to provide healthier food options to students, one of which is through school canteen (Woods et al., 2014). In the process, however, a number of obstacles in implementing the school canteen policies are often reported, including insufficient resources and a lack of knowledge and skills to identify and classify healthy foods appropriately consistent with policy requirements (Ardzejewska, Tadros and Baxter, 2012). Interventions to resolve the barriers are needed in order to facilitate the policy implementation and optimize the potential benefits to children nutrition. One of which is due to nutrition problems, especially malnutrition as one of the main health challenges in community affecting academic achievement (Asmare et al., 2018). Currently, little is known about the range, scope, or common activities of a comprehensive nutrition intervention, and whether such strategies can successfully improve the implementation of healthy school canteen policy. The objectives of this systematic review were to describe the characteristics of evaluated comprehensive nutrition interventions and identify the common components of the interventions that show successful outcomes.

\section{SUBJECTS AND METHOD}

\section{Study Design}

This systematic review was conducted from two electronic databases, namely Scopus and ProQuest published from 2015 to 2020. The keywords of "school nutritional policy", "comprehensive intervention", and "healthy canteen" and have open access was used to search relevant publication in English.

\section{Inclusion and Exclusion Criteria}

The inclusion criteria in this study were comprehensive scientific journals published in the last 5 years (2015-2020) under the condition that the study discussion scope constitutes nutrition intervention in schools, either elementary schools or secondary schools, with the explanation on the intervention characteristics and evaluation on the implementation of healthy school canteen policy. Comprehensive means thorough, integrated, multilevel, multicomponent, or multistrategic.

\section{Data Extraction}

This study using PRISMA 2009 Flow Diagram for data extraction. Because of the varied study designs and models, a common summary measure in this study showed a positive, a negative, or no impact on the desired outcomes.

\section{RESULTS}

\section{Study Characteristic}

The type of intervention that implemented and its evaluation were summarized in table 1. All studies were conducted in elementary schools $(n=8)$ and middle school $(n=1)$. The majority of the studies were located in Australia $(n=6)$ and others were identified in Netherlands $(\mathrm{n}=1)$, Slovenia $(\mathrm{n}=1)$, and Malaysia $(n=1)$. The studies conducted in Australia were mostly integrated with the New South Wales Healthy School Canteen Policy or known as Fresh Tastes @ School. In Netherlands, this study was integrated with the Dutch Healthy School Canteen Program, 
while in Slovenia with School Meals Act, and Malaysia with School Nutrition Program. The earliest intervention started in 2011 and the recent one started in 2016.

\section{Size and target populations}

The size of participants in the selected studies were varied from 20-400 schools with at least 1 program. Age range varied in each country according to the study target (students' age, canteen waitress, school, or any other stakeholders), but still reflected in the scope of elementary school or middle school.

\section{Activities}

Overall, interventions used a wide range of activities and approaches. Duration and intensity of interventions also varied substantially, from a couple of months to several years. From 2 electronic databases (Scopus and ProQuest), 1.367 journals were identified. From 35 selected journals, the remaining 16 journals were selected according to their feasibility complying with the inclusion criteria. All journals were investigating about comprehensive nutrition intervention in school, but only 9 studies discussing further about the effectiveness of healthy school canteen policy (Figure 1).

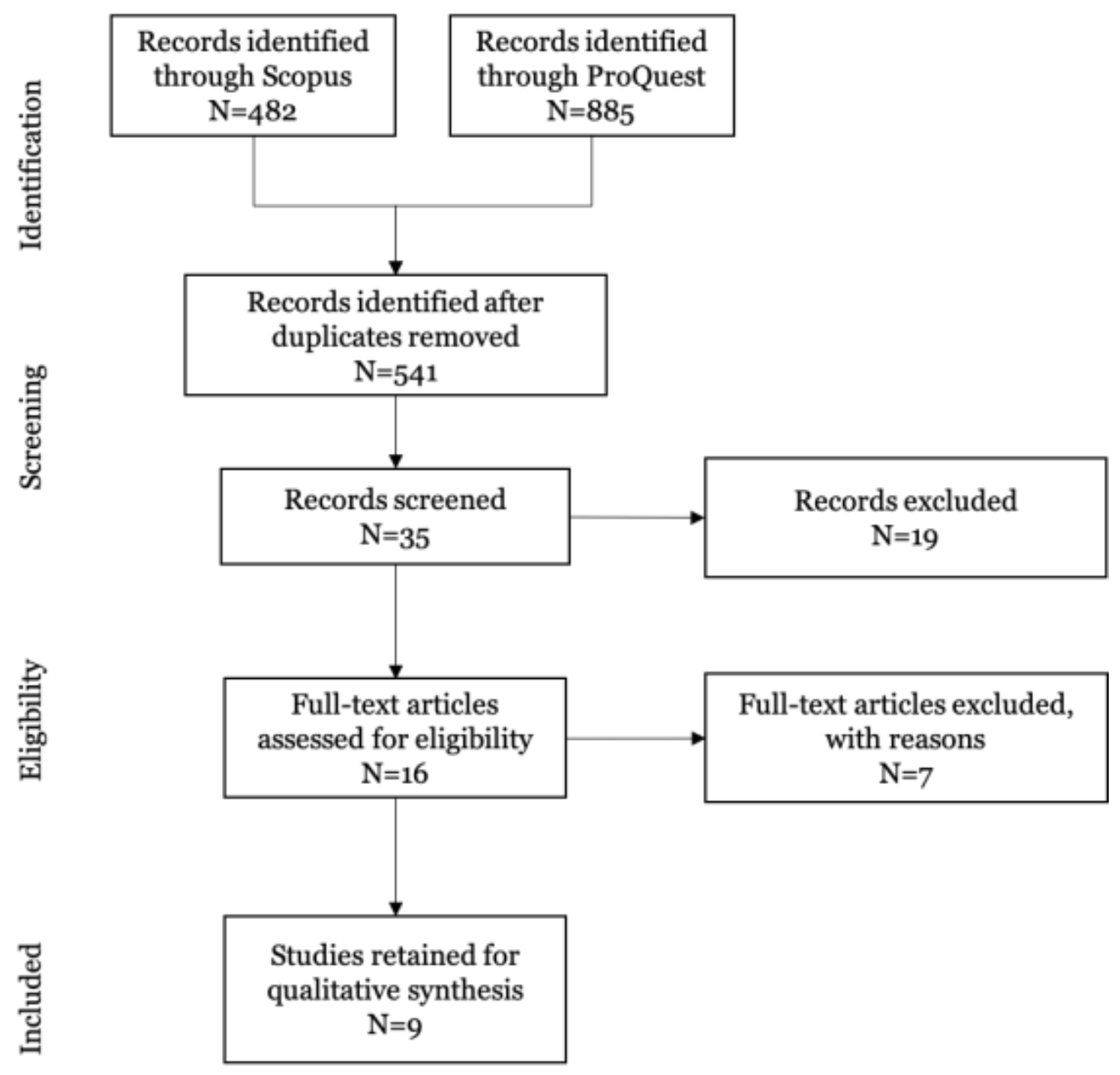

Figure 1. PRISMA 2009 Flow Diagram of search and data extraction 
Table 1. Summary of Characteristics of a Comprehensive School-Based Nutrition Intervention in Improving the Implementation of Healthy School Canteen Policy

\begin{tabular}{|c|c|c|c|c|}
\hline \multirow{2}{*}{ Authors } & \multirow{2}{*}{ Title } & \multirow{2}{*}{ Location } & \multicolumn{2}{|c|}{ Results } \\
\hline & & & Intervention Characteristics & Evaluation and Significant Results \\
\hline $\begin{array}{l}\text { Evenhuis } \\
\text { et al. } \\
\text { (2019) }\end{array}$ & $\begin{array}{l}\text { Implementation of } \\
\text { guidelines for healthier } \\
\text { canteens in Dutch } \\
\text { secondary schools: A } \\
\text { process evaluation }\end{array}$ & $\begin{array}{l}\text { Secondary } \\
\text { schools, The } \\
\text { Netherlands }\end{array}$ & $\begin{array}{l}\text { Implementing several tools aimed to imple- } \\
\text { ment the Guidelines for Healthier Canteens } \\
\text { by providing insight into the current situation } \\
\text { with questionnaire for school and } \\
\text { stakeholders, canteen scan, advisory meeting } \\
\text { and report, improving communication } \\
\text { materials, establishing online community, } \\
\text { digital newspaper, and students fact sheet. }\end{array}$ & $\begin{array}{l}\text { The tools to implement the guidelines seem to } \\
\text { result in positive changes, either to individual } \\
\text { and environmental factors affecting } \\
\text { implementation. First, it showed more specific, } \\
\text { knowledge, descriptive norm, motivation, and } \\
\text { perceived organisational support increased, and } \\
\text { need for support of stakeholders decreased } \\
\text { (more independence). Second, stakeholders } \\
\text { evaluated the implementation tools positively. } \\
\text { These results are in line with Australian studies } \\
\text { concerning that implementation of healthy } \\
\text { school canteen policy can be applied in most } \\
\text { schools with multi-strategic support, monitoring, } \\
\text { and feedback. }\end{array}$ \\
\hline $\begin{array}{l}\text { Nathan et } \\
\text { al. (2016) }\end{array}$ & $\begin{array}{l}\text { Effectiveness of a } \\
\text { multicomponent inter- } \\
\text { vention to enhance } \\
\text { implementation of a } \\
\text { healthy canteen policy } \\
\text { in Australian primary } \\
\text { schools: a randomised } \\
\text { controlled trial. }\end{array}$ & $\begin{array}{l}\text { Primary } \\
\text { schools, } \\
\text { Australia }\end{array}$ & $\begin{array}{l}\text { Implementing a 9-month multi-component } \\
\text { intervention including in the application of } \\
\text { healthy school canteen policy, including on } \\
\text { going support, provision of resources, } \\
\text { performance monitoring and feedback, } \\
\text { executive support and recognition. }\end{array}$ & $\begin{array}{l}\text { A multi-component intervention was effective in } \\
\text { improving primary schools compliance with a } \\
\text { healthy canteen policy. } \\
\text { The use of telephone and text messaging support } \\
\text { employed in this trial enhances the potential } \\
\text { scalability of this intervention, thereby providing } \\
\text { novel information for public health policy } \\
\text { makers and practitioners regarding strategies to } \\
\text { facilitate the implementation of nutrition policies } \\
\text { and guidelines broadly, and healthy canteen } \\
\text { policies specifically. }\end{array}$ \\
\hline $\begin{array}{l}\text { Reilly et } \\
\text { al. (2018) }\end{array}$ & $\begin{array}{l}\text { Scale up of a multi- } \\
\text { strategic intervention to } \\
\text { increase implement- } \\
\text { ation of a school }\end{array}$ & $\begin{array}{l}\text { Primary } \\
\text { schools, } \\
\text { Australia }\end{array}$ & $\begin{array}{l}\text { Implementing multi-strategic intervention at } \\
\text { scale including leadership support, consensus } \\
\text { process, education, tools and resources, } \\
\text { provision of implementation support, }\end{array}$ & $\begin{array}{l}\text { This study found a positive improvement in } \\
\text { nutrition policy implementation across entire } \\
\text { populations of schools. School canteen } \\
\text { compliance with a healthy food policy increased }\end{array}$ \\
\hline
\end{tabular}


healthy canteen policy: findings of an intervention trial

Wofelden Multi-strategic inter-

et al.

(2018)

Yoong et al. (2016) canteens: a randomised

Reilly et Economic analysis of al., (2018) three interventions of

Wolfende Two-year follow-up of a $\mathrm{n}$ et al. (2019) vention to enhance implementation of healthy canteen policy: a randomised controlled trial

CAFÉ: A multicompointervention to improve implementation of healthy food policy in primary school controlled trial. different intensity in improving school implementation of a government healthy canteen policy in Australia: costs, incremental and relative cost effectiveness (Reilly,

Reeves, et al., 2018) randomised controlled

Primary schools, Australia

\section{schools,} Australia trial to assess the sustainability of a

Primary schools, Australia

Primary schools, Australia reinforcement, audit and feedback, and canteen product database.

Multi-strategic interventions included allocation of support officer to assist with policy implementation, engagement of school principals and parent committees, consensus processes with canteen managers, training, provision of tools and resources, academic detailing, performance feedback, recognition, and marketing initiatives.

The main intervention components included a menu audit and subsequent provision of feedback ( 1 to 4 times over a 12 months period) via a written report and telephone call.

The three trials employed intervention strategies of varying intensity defined according to the three levels of labor support provided by school support officers and number of strategies for the 'high', 'medium', and 'low' intensity.
A 12-14 months multi-strategic intervention The intervention was positive/effective in to support canteen policy implementation achieving long-term school adherence to a stateincluded allocation of a support officer to wide canteen policy at 24-month follow up. in association with a multi-strategy intervention delivered at scale.

With multi-strategic support, implementation of healthy canteen policies can be successfully applied in the vast majority of schools (>70\%). The findings suggest that the intervention was successful in overcoming many of the barriers that reportedly hinder nutrition policy implementation in schools previously.

The study found that a multicomponent audit and feedback intervention did not significantly increase the proportion of rural and remote schools within the region that had more than $50 \%$ "green" items on their menus. The intervention also resulted in an positive change in menu composition in terms of a reduction in the availability of unhealthy foods.

The 'high' intensity intervention incurred the greatest costs per school, followed by the 'medium' and the 'low' intensity intervention. However, the comparison between the 'high' and 'medium' intensity interventions showed no statistically significant difference between the two in cost-effectiveness. 
school intervention to improve the implementation of a schoolbased nutrition policy.

Gregorič School nutrition guideet al. lines: overview of the

(2015) implementation and evaluation.

Teo et al. (2019)

School-based intervention that integrates
Primary schools, Slovenia nutrition education and supportive healthy school food environment among Malaysian primary school children: a study protocol.

Primary schools, Malaysia principals and parent committees, consensus processes with canteen managers, training, provision of tools and resources, academic detailing, performance feedback, and recognition and marketing initiatives.

The National Dietary Guidelines for Healthy Nutrition in Kindergartens and Schools were adopted as part of a comprehensive "School Meals Act" with three different approaches, included a survey among school food-service managers for process evaluation, an indicator-based evaluation of menu quality, and nutritional assessment of school meals for output evaluation. School Nutrition Programme (SNP) intervention consisted of 2 main components: delivering nutrition education through School Nutrition Campaign for 3 months and serving healthy menu during school recess time to the children over a period of 3 months.
The evaluation of the implementation showed evidence that some school characteristics such as size, location, and socio-economic environment can play an important role in implementation procedures. Positive results were found in largersized schools and corresponding municipalities with higher socio-economic status.

The result showed that 3 months period was effective to improve knowledge, attitude and practices on nutrition, eating behaviours, physical activity, anthropometric assessments, psychological distress, cognitive performance, and health-related quality of life among Malaysia primary school children. However, food handlers had a significantly lower food nutrition knowledge score than the general public. 


\section{DISCUSSION}

In the last few years, various health policies on school-based nutrition intervention have been implemented in countries around the world as recommended by the World Health Organization in order to improve children nutrition. Several improvements were also applied to the implementation that was selfidentified as a comprehensive program. Moreover, any obstacle such as study resource needs to be underlined, in which most programs included in the study based reviews in developed countries as Australia. Lee-Rife et al., (2012) stated that the lack of program and complex evaluation in middle and low income countries are most likely reflecting the lack of infrastructure and weak economy of the community. One thing that could be highlighted was the implementation of healthy school canteen policy.

Observing from the school-based nutrition intervention studied and stated effective further, in regard to improving the healthy school canteen policy, it can be seen that the interventions are different in terms of approach, activity, population, purpose, and scope. However, it is hard to compare them directly due to the difference of varied culture, economy, social, and politic where the policy is implemented. By understanding the empirical basis where the study is developed, it is reasonable to believe that the elements represent a good starting point in a comprehensive intervention development in each country. This research elaborated numerous schoolbased nutrition interventions performed by the policy holders explicitly having the healthy school canteen guidelines in their countries. Along the program implementation, many innovations or evaluations have been performed.

From this study, the common elements of a comprehensive school-based nutrition intervention have been shown to inhance the implementation of healthy school canteen policy. First, communication improvement through regular monitoring and feedback is one of the key points in this matter, considering the benefit of the improvement that can be seen in the changes to the individual or environment implementing the healthy school canteen (Evenhuis et al., 2019). Actions related to that point are advisory meeting and report (e.g compliance, etc), students fact sheets, and also support services by text messages, phone, or online services. The study result in Netherlands was also in line with the studies in Australia stating that the implementation of healthy school canteen policy can be achieved with multi-strategic support, including personal support, monitoring, and feedback (Nathan et al., 2016); (Wolfenden et al., 2017) . However, in one of the studies conducted in Australia, Yoong et al., (2016) stated that the intervention of feedback improvement is insignificantly increasing in rural and excluded schools. Yet, the decrease in unhealthy foods/beverages quantity in canteen is a significant positive impact.

Second, executive and community support in order to improve better services are another quite significant factor. The involvement of headmaster, parents committee, canteen manager that will promote the implementation of the healthy canteen policy in a longterm basis, as well as contribute improvement to the implementation of the school cross population nutrition policy (Wolfenden et al., 2019). In addition, reward and regular training workshop also constitutes an innovation with positive impact for healthy school canteen.

Another approach of the study conducted in Slovenia concluded that the interventions mentioned above put trust on the school characteristics, such as the size, area and socio-economic environment of the school (Adamson et al., 2013). Further, the best result can be seen in the schools with 
high socio-economic status (Gregorič et al., 2015). Another study approach in regard to the school-based nutrition intervention that needs to be understood is cost-effectiveness, where in some high and intermediate support levels there is no significant difference (Reilly, Reeves, et al., 2018). This result is valuable to policy makers seeking costeffective solutions that can be delivered within budget.

The limitation in this study was the method that only used 2 electronic databases. In addition, the search limitation is only in the healthy school canteen policy. The selected studies were less representing the variation in other countries that probably has different program or policy. It became the consequence in the identification of common components having limited range in terms of affecting the implementation of an effective healthy school canteen.

The result of this study indicates that the nutrition intervention in schools performed comprehensively may improve the implementation of healthy school canteen more effective. Whereas the common comprehensive elements are periodic communication improvement through regular monitoring, and also executive and community support needs. In the implementation, however, there are different limitations in each country. It is suggested to perform trials in the future study with a more comprehensive strategy to increase the implementation of healthy school canteen policy, such as from developing and developed countries, urban and rural area, as well as with a strong evidence level quality. This is solely to obtain the best result in order to support the schoolbased nutrition intervention.

\section{AUTHOR CONTRIBUTION}

Sarah At Tauhidah as the main researcher has a roll in collecting data and wrote the scripts; Cicilya Candi developed the ideas and designed the study; Adang Bachtiar examined the results of the study and provided material in the discussion.

\section{CONFLICT OF INTEREST}

There was no conflict of interest.

\section{FUNDING AND SPONSORSHIP}

None

\section{ACKNOWLEDGEMENT}

The author would like to thank to Cicilya Candi and Adang Bachtiar for their cooperation and patience to compile this study together.

\section{REFERENCE}

Adamson A, Spence S, Reed L, Conway R, Palmer A, Stewart E, McBratney J, et al. (2013). School food standards in the UK: Implementation and evaluation. Public Health Nutrition. 16(6): 968981. doi: 10.1017/S1368980013000621.

Afshin A, et al. (2019). Health effects of dietary risks in 195 countries, 19902017: a systematic analysis for the Global Burden of Disease Study 2017. The Lancet. 393(10184): 1958-1972. doi: 10.1016/So140-6736(19)30041-8.

Ardzejewska K, Tadros R, Baxter D (2012). A descriptive study on the barriers and facilitators to implementation of the NSW (Australia) Healthy School Canteen Strategy. Health Education Journal. 72(2): 136-145. doi: 10.1177/0017896912437288.

Asmare B, Taddele M, Berihun S, Wagnew F, (2018). Nutritional status and correlation with academic performance among primary school children, northwest Ethiopia. BMC Research Notes. 11(1): 1-6. doi: 10.1186/s13104-018-3909-1.

Briggs M, Fleischhacker S, Mueller CG (2010). Position of the American Dietetic Association, School Nutrition Asso- 
ciation, and Society for Nutrition Education: Comprehensive School Nutrition Services. Journal of Nutrition Education and Behavior. 42(6): 360-371. doi: 10.1016/j.jneb.2010.08.007.

Carter MA, Swinburn B (2004). Measuring the "obesogenic" food environment in New Zealand primary schools. Health Promot Int. 19(1): 15-20. doi: 10.1093/heapro/dah103.

Evenhuis IJ, Vyth EL, Veldhuis L, Jacobs SM, Seidell JC, Renders CM (2019). Implementation of guidelines for healthier canteens in dutch secondary schools: A process evaluation. Int $\mathrm{J}$ Environ Res and Public Health. 16(22): 4509. doi: 10.3390/ijerph16224509.

Gregorič M, Pograjc L, Pavlovec A, Simčič M, Blenkuš MG (2015). School nutrition guidelines: Overview of the implementation and evaluation. Public Health Nutr. 18(9): 1582-1592. doi: 10.1017/S1368980014003310.

Initiatives D (2020). Global Nutrition Report, The Global Nutrition Report's Independent Expert Group.

Lee-Rife S, Malhotra A, Warner A, Glinski AM (2012). What works to prevent child marriage: a review of the evidence. Stud Fam Plann. 43(4): 287-303. doi: 10.1111/j.1728-4465.2012.00327.x.

Nathan N, Yoong SL, Sutherland R, Reilly K, Delaney T, Janssen L, Robertson K, et al. (2016). Effectiveness of a multicomponent intervention to enhance implementation of a healthy canteen policy in Australian primary schools: A randomised controlled trial. International Journal of Behavioral Nutrition and Physical Activity. International Journal of Behavioral Nutrition and Physical Activity. 13(1): 1-9. doi: 10.1186/s12966-016-0431-5.

Reilly KL, Reeves P, Deeming S, Yoong SL, Wolfenden L, Nathan N, Wiggers J
(2018). Economic analysis of three interventions of different intensity in improving school implementation of a government healthy canteen policy in Australia: Costs, incremental and relative cost effectiveness. BMC Public Health. 18(1): 1-9. doi: 10.1186/s12889-018-5315-y.

Reilly KL, Nathan N, Wiggers J, Yoong SL, Wolfenden L (2018). Scale up of a multi-strategic intervention to increase implementation of a school healthy canteen policy: Findings of an intervention trial. BMC Public Health. 18(1): 1-10. doi: 10.1186/s12889-018-5786-x.

Teo CH, Chin YS, Lim PY, Masrom SAH, Shariff ZM (2019). School-based intervention that integrates nutrition education and supportive healthy school food environment among Malaysian primary school children: a study protocol. BMC public health. 19(1): 1427. doi: 10.1186/s12889-019-7708-y.

WHO (2013). Global action plan for the prevention and control of noncommunicable diseases 2013-2020. World Health Organization.

Wolfenden L, Nathan N, Janssen LM, Wiggers J, Reilly K, Delaney T, Williams CM, et al. (2017). Multi-strategic intervention to enhance implementation of healthy canteen policy: A randomised controlled trial. Implementation Science. 12(1): 1-11. doi: 10.1186/s13012016-0537-9.

Wolfenden L, Nathan N, Reilly K, Delaney T, Janssen LM, Reynolds R, Sutherland R, et al. (2019). Two-year follow-up of a randomised controlled trial to assess the sustainability of a school intervention to improve the implementation of a school-based nutrition policy. Health Promotion Journal of Australia. 30(1): 26-33. doi: 10.1002/hpja.238.

Woods J, Bressan A, Langelaan C, Mallon A, 
Tauhidah et al./ Implementation of Healthy School Canteen Policy

Palermo C (2014). Australian school canteens: Menu guideline adherence or avoidance?. Health Promot J Australia. 25(2): 110-115. doi: 10.1071/HE14009. Williams CM, Nathan N, Delaney T, Yoong SL, Wiggers J, Preece S, Lubans N, et al. (2016). CAFÉ: A multicomponent audit and feedback intervention to improve implementation of healthy food policy in primary school canteens: A randomised controlled trial. BMJ Open. 13(1): 1-11. doi: 10.1186/s12966o16-0453-z. 